\title{
HETACILINA EM DOSE ÚNICA NO TRATAMENTO DA GONORRÉIA
}

J. Martins de BARROS (1)

Jairo P. de MENEZES (2)

Barros, J. M. DE \& Menezes, J. P. DE - Hetacilina em dose única no tratamento da gonorréia. Rev. Saúde puibl., S. Paulo, 5:47-50, 1971.

Resumo - Foram tratados 155 pacientes do sexo masculino, portadores de uretrite gonocócica aguda, com $3,0 \mathrm{~g}$ de Hetacilina $\mathrm{K}$ por via oral ( 70 casos) ou $1,0 \mathrm{~g}$ do mesmo medicamento por via intramuscular ( 85 casos). Em $88,6 \%$ dos casos tratados pela via oral, e em $93 \%$ dos casos tratados com uma injeção intramuscular, o coirimento desapareceu em um tempo médio de 48 horas. Não foram observadas reações de intolerância ao medicamento.

UNITERMos - Hetacilina*; Gonorréia*; Antibióticos *.

Hetacilina é um antibiótico de largo espectro. Quìmicamente é um penicinato, cuja ação contra bactérias já foi demonstrada in vitro e in vivo.

Barros e colabs. ${ }^{1}$ (1968),Puchi Ferrer e colabs. ${ }^{4}$ (1969), Rodrigues Duarte ${ }^{5}$ (1969), Tuano e colabs. ${ }^{6}$ (1966), FloRES e colabs. ${ }^{3}$ (1969), entre outros, demonstraram a eficácia da Hetacilina no tratamento da infecção gonocócica aguda.

Em 1969, Menezes e Ximenes ${ }^{(3)}$ demonstraram que uma injeção por via intramuscular de $1,0 \mathrm{~g}$ de Hetacilina potássica dava, 2 horas depois, uma concentração média superior a $10,0 \mathrm{mcg} / \mathrm{ml}$, no sôro dos pacientes em observação, $\mathrm{e}$ que 12 horas após ainda havia quantidade suficiente, em nível sorológico, para inibir o crescimento do $N$. gonorrhoeae in vitro.

Essas características relevantes da ação da hetacilina potássica sôbre o $N$. ga norrhoeae levaram os autôres a um nôvo estudo comparativo da ação dêsse antibiótico, por via oral e por via intramuscular, em portadores de gonorréia aguda.

Material de estudo:

Foram tratados portadores de gonorréia, todos do sexo masculino, no Serviço de Venéreas do Centro de Saúde da Faculdade de Saúde Pública USP e Serviço

Recebido para publicação em 16-3-1971.

(1) Do Departamento de Epidemiologia da Faculdade de Saúde Pública da USP - Av. Dr. Arnaldo, 715 - São Paulo, SP - Brasil.

(2) Da Secretaria de Higiene da Prefeitura Municipal. Parque Ibirapuera, São Paulo, SP Brasil.

(3) Trabalho elaborado no Departamento de Microbiologia Clínica da Divisão Médica da Laborterápica Bristol S.A. - Niveis séricos obtidos com a administração de doses únicas de Hetacilina $\mathrm{K}-1 \mathrm{~g}$ por via intramuscular em 10 voluntários normais, niveis séricos obtidos com a administração de doses únicas de Hetacilina $K-3 g$ por via oral e Ampicilina Trihidratada $-\mathbf{3} \mathrm{g}$ por via oral. (Dados inéditos). 
BARROS, J. M. de \& MENEZES, J. P. de - Hetacilina em dose única no tratamento da gonorréla. Rev. Saúde públ., S. Paulo, 5:47-50, 1971.

de Sífilis dos Centros de Saúde da Capital. Dêsses, foram relacionados 155 casos, por apresentarem tempo médio de observação de 15 dias.

\section{Diagnóstico:}

O diagnóstico foi feito por meio de esfregaço e cultura de secreção uretral colhida por ocasião do exame. 0 esfregaço era corado pelo método de Gram e a cultura feita em meios de agar sangue e chocolate.

\section{Contrôle pós-tratamento:}

Os pacientes eram examinados no $3 .^{\circ}$ e no $15 .^{\circ}$ dia após o tratamento, recomendando-se abstinência sexual durante o período de observação. Esfregaço e cultura eram realizados nos casos que apresentavam qualquer secreção uretral. $\mathrm{Na}$ véspera do último exame, a maioria dos pacientes tomou um copo de cerveja.

\section{Critério de cura:}

Os pacientes que no $15 .^{\circ}$ dia pós-tratamento não apresentavam nenhum sinal de corrimento uretral, foram considerados clinicamente curados.

Os pacientes que, durante o periodo de observação, apresentaram secreção uretral de qualquer intensidade, porém sem presença de $N$. Gonorrhoeae nos exames de esfregaço e cultura, eram considerados como bacteriològicamente curados. Tratava-se, via de regra, de uretrite pós-gonocócica por estafilococos, estreptococos ou micrococos sp.

\section{Esquemas de tratamento:}

A - Via oral: 3,0 g. de Hetacilina K tomadas de uma só vez.

B - Via intramuscular: 1,0 g. de Hetacilina $K$ em uma única injeção.

Foram seguidos 155 casos de uretrite gonocócica aguda, sendo que 70 recebe- ram o medicamento por via oral e 85, por via parenteral.

Os pacientes estavam assim discriminados:

1. Quanto à idade:

\begin{tabular}{l|r|r|r|r}
\hline \multirow{2}{*}{ Idade } & \multicolumn{2}{|c|}{ Via oral } & \multicolumn{2}{|c}{$\begin{array}{c}\text { Via intra- } \\
\text { muscular }\end{array}$} \\
\cline { 2 - 6 } & N.0 & $\%$ & N.0 & $\%$ \\
\hline $161-20$ anos & 14 & 20,0 & 12 & 14,0 \\
$201-30$ anos & 41 & 58,6 & 6,3 & 78,0 \\
40 e mais & 13 & 18,6 & 4 & 4,6 \\
\hline & 2 & 2,8 & 3 & 3,4 \\
Total & 70 & 100,0 & 85 & 100,0 \\
\hline
\end{tabular}

2. Quanto ao tempo de moléstia:

\begin{tabular}{|c|c|c|c|c|}
\hline \multirow{2}{*}{$\begin{array}{l}\text { Tempo de } \\
\text { moléstia }\end{array}$} & \multicolumn{2}{|c|}{ Via oral } & \multicolumn{2}{|c|}{$\begin{array}{l}\text { Via intra- } \\
\text { muscular }\end{array}$} \\
\hline & N.o & $\%$ & N.o & $\%$ \\
\hline menos de 8 dias & 59 & 84,3 & 61 & 71,8 \\
\hline 8 a 15 dias & 10 & 14,3 & 23 & 27,0 \\
\hline 15 dias e mais & 1 & 1,4 & $I$ & 1,2 \\
\hline Total & 70 & 100,0 & 85 & 100,0 \\
\hline
\end{tabular}

3. Quanto ao tratamento anterior:

\begin{tabular}{l|r|r|r|r} 
& & Via oral & \multicolumn{2}{|c}{$\begin{array}{c}\text { Via intra- } \\
\text { muscular }\end{array}$} \\
\cline { 2 - 5 } Tratamento & N.0 & $\%$ & N.0 & $\%$ \\
\hline $\begin{array}{l}\text { Sem tratamento } \\
\text { anterior } \\
\text { Com algum tra- } \\
\text { tamento ante- } \\
\text { rior }\end{array}$ & 50 & 71,5 & 58 & 68,2 \\
\hline \begin{tabular}{l} 
Total \\
\hline
\end{tabular} & 70 & 100,0 & 85 & 100,0 \\
\hline
\end{tabular}


BARROS, J. M. de \& MENEZES, J. P. de - Hetacilina em dose única no tratamento da gonorréia. Rev. Saúde públ., S. Paulo, 5:47-50, 1971.

4. Quanto ao tempo observado para o desaparecimento total do corrimento:

\begin{tabular}{|c|c|c|c|c|}
\hline \multirow{2}{*}{ Tempo } & \multicolumn{2}{|c|}{ Via oral } & \multicolumn{2}{|c|}{$\begin{array}{l}\text { Via intra- } \\
\text { muscular }\end{array}$} \\
\hline & N.O & $\%$ & N.o & $\%$ \\
\hline 24 horas & 6 & 8,6 & 14 & 16,5 \\
\hline 48 horas & 40 & 57,0 & 56 & 66,0 \\
\hline 72 horas & 16 & 23,0 & 9 & 10,5 \\
\hline $\begin{array}{l}\text { sem desapareci- } \\
\text { mento }\end{array}$ & 8 & 11,4 & 6 & 7,0 \\
\hline Total & 70 & 100,0 & 85 & 100,0 \\
\hline
\end{tabular}

\section{Resultados do tratamento:}

\section{A - Via oral:}

O corrimento cessou totalmente em 58 casos $(83 \%)$, considerados como cura clínica e bacteriológica.

Em 4 casos houve persistência de corrimento, em geral mucohialino, sem a presença de $N$. gonorrhoeae nos exames de esfregaço ou cultura, tendo sido observado o crescimento de estafilococos, estreptococos ou micrococos sp. Esses casos foram considerados como cura bacteriológica $(5,6 \%)$.

Em 5 casos $(7,1 \%)$ o corrimento cessou mas recidivou entre o $2 .^{\circ}$ e o $5 .^{\circ}$ dia de observação, e não cessou em 3 casos $(4,3 \%)$, sendo detectada a presença de $N$. gonorrhoeae nos exames de esfregaço e cultura. Esses casos foram considerados como insucesso terapêtutico.

0 tempo médio para o desaparecimento do corrimento foi de 48 horas, sendo que em 8,6 dos casos cessou em 24, horas.

\section{B - Via intramuscular:}

O corrimento cessou totalmente em 73 casos (86\%), considerados como cura clínica e bacteriológica.

Em 6 casos $(7 \%)$ houve persistência de corrimento, em alguns casos com cura espontânea de 5 a 12 dias. Não foi detectada a presença de $N$. gonorrhoeae nos exames de esfregaço e cultura, mas sim de estafilococos, estreptococos ou micrococos sp. Esses casos foram considerados como cura bacteriológica.

Em 4, casos $(4,7 \%)$ o corrimento recidivou do $2 .^{\circ}$ ao $5 .^{\circ}$ dia de observação, e em 2 casos $(2,4 \%)$ não cessou. Em todos os casos foi possível demonstrar a presença de $N$. gonorrhoeae em exames de esfregaço e cultura. Esses casos foram considerados como insucesso terapêutico.

O tempo médio para o desaparecimento do corrimento foi de 48 horas, sendo que em $16,5 \%$ dos casos cessou em 24 horas.

\begin{tabular}{|c|c|c|c|c|}
\hline \multirow{2}{*}{ Resultado do tratamento } & \multicolumn{2}{|c|}{ Via oral $(3,0 \mathrm{~g})$} & \multicolumn{2}{|c|}{$\begin{array}{l}\text { Via intramuscular } \\
(1,0 \mathrm{~g})\end{array}$} \\
\hline & $\begin{array}{l}\text { N.o de } \\
\text { casos }\end{array}$ & $\%$ & $\begin{array}{l}\text { N.o de } \\
\text { casos }\end{array}$ & $\%$ \\
\hline $\begin{array}{l}\text { Corrimento cessou totalmente (cura clínica e bacte- } \\
\text { riológica) }\end{array}$ & 58 & 83,0 & 73 & 86,0 \\
\hline $\begin{array}{l}\text { Corrimento pós-tratamento sem gonococos (cura } \\
\text { bacteriológica) }\end{array}$ & 4 & 5,6 & 6 & 7,0 \\
\hline $\begin{array}{l}\text { Corrimento cessou mas recidivou 2-5 dias após com } \\
\text { gonococos (insucesso) }\end{array}$ & 5 & 7,1 & 4 & 4,7 \\
\hline Persistencia de corrimento (insucesso) & 3 & 4,3 & 2 & 2,3 \\
\hline Total & 70 & 100,0 & 85 & 100,0 \\
\hline
\end{tabular}


BARROS, J. M. de \& MENEzES, J. P. de - Hetacilina em dose única no tratamento da gonorréia. Rev. Saude públ., S. Paulo, s:47-50, 1971.

\begin{tabular}{|c|c|c|c|c|}
\hline \multirow{2}{*}{ Resultado geral do tratamento } & \multicolumn{2}{|c|}{ Via oral $(3,0 \mathrm{~g})$} & \multicolumn{2}{|c|}{$\begin{array}{l}\text { Via intramuscular } \\
(1,0 \mathrm{~g})\end{array}$} \\
\hline & $\begin{array}{l}\text { N.p de } \\
\text { casos }\end{array}$ & $\%$ & $\begin{array}{l}\text { N.o de } \\
\text { casos }\end{array}$ & $\%$ \\
\hline Cura clínica e/ou bacteriológica & 62 & 88,6 & 79 & 93,0 \\
\hline Insucesso terapeutico & 8 & 11,4 & 6 & 7,0 \\
\hline Total & 70 & 100,0 & 85 & 100,0 \\
\hline
\end{tabular}

Em 62 dos 70 casos de gonorréia aguda tratados com $3,0 \mathrm{~g}$ de Hetacilina potássica por via oral, houve cura clínica e bacteriológica ou cura bacteriológica, o que significa $88,6 \%$ de sucesso terapêutico.

Em 79 dos 85 casos de gonorréia aguda tratados com uma injeção intramuscular de 1,0 g de Hetacilina potássica, houve cura clínica e bacteriológica ou cura bacteriológica, o que significa $93 \%$ de sucesso terapêutico.

Insucesso terapêutico foi observado em $11,3 \%$ dos casos tratados por via oral $\mathrm{e}$ $7 \%$ dos casos tratados por via parenteral.

Barros, J. M. de \& Menezes, J. P. DE [Hetacillin in a single dose in the treatment of gonorrhoeae]. Rev. Saúde puibl., S. Paulo, 5:47-50, 1971

SUMmary - Schemes of treatment with one single parenteral injection or single oral dosis of a broad spectrum antibiotic - Hetacillin - has been employed in 155 patients with acute gonorrhoeae who were, then, followed-up during 15 days in the Service of VD of the School of Public Health, University of São Paulo. The diagnosis and control of the cases were performed through smears and cultures of the urethral discharge. Cure has been attained in $88,6 \%$ of 70 patients treated with $3.0 \mathrm{~g}$ of Hetacillin by oral route, in a single dosis, and in $93 \%$ of 85 patients treated with one single intramuscular injection of Hetacillin (1.0 g). Discharge has disappeared in an average of 48 hours in both schedules of treatment. No side effects or toxicity were observed.

UNITERMS - Hetacillin *; Gonorrhoeae *; Antibiotics *

\section{REFERENCIAS BIBLIOGRAFICAS}

1. BARROS, J. M. de et al. - Tratamento da gonorréia com Hetacilina. In:SIMPOSTO SÓBRE PENICILINA SEMI-SINTETTCA E NOVOS ANTTBIóticos, São Paulo, 1967. - Anais. São Paulo, 1968. p. 110-17.

2. BUNN, P. A. et al. - Pharmacological properties of hetacillin in the human. Antimicrob. Agents Chemother. 1965: 947-50, 1966 .

3. FLORES, E. J. et al. - Uso clínico de um penicinato (Hetacilina - BI P.804) por via intramuscular no tratamento da blenorragia. Estudo de 50 pacientes. Rev. bras. Pesq. méd. biol., 2:141-43, 1969.

4. PUCHI FERRER, J. A. et al. - Avaliação clínica da hetacilina por via oral em 180 pacientes com utetrite gonocócica. Rev. bras. Pesq. méd. biol. 2:135$40,1969$.

5. RODRIGUES DUARTE, c. et al. - Estudo comparativo do efeito terapêutico de um regime de doses únicas de Hetacilina e Ampicilina na uretrite gonocócica. Hospital, Rio de Janeiro, 75:979-86, 1969.

6. TUANO, S. B. et al. - Comparative blood levels of hetacillin, ampicillin and penicillin G. New Engl. J. Med., 275: 635-39, 1966. 